\title{
Constructivist Pedagogy For The Business Communication Classroom
}

\author{
Minu Mathews, (E-mail: minu@squ.edu.om), Sultan Qaboos University, Sultanate of Oman
}

\begin{abstract}
Business education and learning has become formidable and challenging over the last few years. A traditional learning environment is bereft of active learning where students only try to memorise terms and concepts and is unable to apply them to the real corporate world. It was found in the business communication classes that students fail to comprehend basic business terminology and communication practices and concepts related to organizational administration and functioning. In such a state of nescience, there was a need to enable the students to maximise learning through knowledge construction in authentic environments that employs the context in which learning is relevant. A suitable teaching method which needs to be dependant on variables such as target audience and content (Gulbahar, 2006) was designed for the business communication classroom that undergrids the theory of constructivism (Piaget, 1963). Constructivism lends to learning that is action-based where learners construe or make interpretations of their world through interactions in the real-world. Students were actively engaged in making sense of different concepts and terms through workplace interactions and observations. This paper therefore describes an example that builds a dichotomy between knowledge and "learning by doing" which was integrated into the business communication curricula in a tertiary educational system of Oman. Qualitative paradigms, such as semi-structured interviews with students, employee feedback, student portfolios were used to evaluate student's cognitive domain.
\end{abstract}

\section{INTRODUCTION}

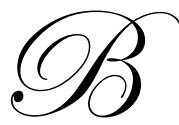

usiness education and learning has become challenging over the last few years. The knowledge gained in university education is met till they write and pass their examinations (Gill \&Lashine, 2003). Transferring knowledge from the classroom to the workplace has become one the most important goal of business education. Basic skill development along with sound knowledge of workplace environment has become crucial in the education scenario. Whilst the most important skills needed for the business graduate in this era of globalization are technical skills, analytical skills, communication skills, multi-disciplinary and inter-disciplinary skills (Gill \& Lashine, 2003) and whereby universities are educating and training students for the labour market to be professionals and business specialists, academicians still face a great challenge in making them comprehend business concepts and theories at the initial levels. Learners find it difficult to cognize theories and concepts inside the classrooms as they are impalpable.

It was noticed that students who enter college and taking the Business Communication Course, a core course, (mostly in their first and second year of college) at the Sultan Qaboos University of Oman face knowledge paucity of concepts related to business studies and their chosen specialization. The instructor would introduce and explain certain simple business concepts and give examples from the workplace related to business communication and its practices from the organizations' perspective and was noticed that students lacked understanding. This was mainly because of the straight transition of these students from school to college where most of them of them haven't even witnessed the work environment scenario until they enter their third or fourth year in college when they undergo training in organizations. Training and internships exists only during the later part and not during the foundation levels of university education. 
It is highly imperative that education instructors be workplace educators involving a corporate education programme at the rudimentary phase where learning can grapple with issues of practice in informal or tacit learning including mentoring programs, coaching, internships, networking, and communities of practice (O'Connor, 2004; Yang \& Lu, 2001). Recognizing this, a need for students to construe their understanding and conceptualise through workplace learning right from the commencement of university education is highly essential. For students to construct their own understanding, a student-centred approach is always the best learning approach where the teacher can be a facilitator and create an authentic learning environment. Several studies have indicated that rotelearning and teacher-centred approach has proved to be ineffective inside the learning environment. A traditional teaching strategy is bereft of active learning. Kolmos (1996) states that "Learning is not like pouring water into the glass, learning is an active process of investigation and creation based on the learner's interest, curiosity and experience and should result in expanded insights, knowledge and skills."

Therefore, it becomes necessary that learning method include authentic tasks at the initial stages of university education wherein it is variable-dependent on target audience and content. The process and product in an educational context should be assessed and properly designed (Gulbahar, 2006) that supports effective learning for the learners. Such effective learning takes place when students are engaged participating in their own learning process through direct observations and interactions with the workplace and its personnel for the purposes of constructed knowledge. This knowledge of constructed entity gives root to the psychological theory of learning known as constructivism.

\section{CONSTRUCTIVIST PEDAGOGY AND INSTRUCTION}

Psychologists like Jean Piaget and Lev Vygotsky have contributed to the basis of constructivist learning. Much debate has been placed on the emphasis of the individual cognitive structuring process (Piaget) and the emphasis on the social effects on learning (Vygotsky). Piaget's work focussed on cognitive structuring of individuals or mechanism of learning, whereby he predicts that children can or cannot understand at different 'ages and stages' (Piaget, 1963). Piaget's theory suggests that humans cannot be 'given' information for long-term understanding and retention but they must 'construct' their own knowledge. Piaget's theory overlooked the effect of the social interaction on learning.

Vygotsky, on the other hand, has focussed on the effects of social interaction, language and culture on learning. This is where Vygotsky's Thought and Language claims, that, "if one takes consciousness as a subject of study; then individual consciousness can be built through relations with others" (Kozulin, 1985). Thus stems Vygotsky's theory of Zone of Proximal Development or zo-ped described as "the distance between the actual development level as determined by independent problem solving and the level of potential development as determined through problem solving under adult guidance or in collaboration with more capable peers" (Vygotsky, 1978). In other words, it means that learners can develop the concepts when confronted with adult or peer collaboration. Society plays an important role for learner development. Vygotsky argued that learning is not merely the assimilation and accommodation of new knowledge by learners, but learners are integrated into a knowledge community (Jonassen, 1999).

Another similar model that revolves around context-dependent learning, known as situated learning by Lave and Wenger (1991) emphasizes that learning is contextual and takes place in a social and physical environment. Further developing the theory of situated learning, Brown, Collins \& Duguid states that cognitive apprenticeship, a paradigm for situated learning model, "enculturate students into authentic practices and social interaction."(Brown et al., 1989). Therefore, progressive learning and participation at work is only learnt while at work (Hodkinson, 2006); and academic institutions can aid students learn from such 'authentic' environments. Smith et al (2002) stresses the importance of the three forms of learning in the workplace as identified by Billet (1993) as acquiring not only propositional knowledge (knowledge about) and procedural knowledge (knowledge how) of learning in the workplace; but much importance also to the dispositional workplace knowledge that emphasize on values and attitudes. 
Conjointly, the above learning theories and models, albeit with variant significance, incite a congruent perspective on learning. Constructivist theory has contributed in creating active learning of real life situations. Constructivism, a psychological and non-positivist learning (Fosnot, 1996), is an approach in which learners, viewed as axial in the learning process, construct new meanings to what they already know. New meanings are mentally constructed as they take the constructivist approach through social processes and action. The central idea of the learning theory of constructivism implies that human beings have no access to objective reality and learners' are constructing their own version (Fosnot, 1996). Constructivism allows independent thinking, framing self-questions for 'discovery', as opposed to objectivist learning. Objective learning supports absorbing and receiving information passively. Therefore, the process of development depends on social interaction and thus in turn would lead to cognitive development. Hence, it is important that the classroom activities should provide means for community learning through social interaction.

The application of constructivism to education rests on the following principles (Fosnot, 1996 p29, 30)

- $\quad$ Learning is development of self-organization and invention on the part of learner

- $\quad$ "Errors" and contradictions facilitates learning through exploring and investigating meaningful contexts

- $\quad$ Reflective abstraction is the driving force of learning

- $\quad$ Dialogue within a community engenders further thinking

- $\quad$ Learning proceeds towards the development of structures

Prior literature affirms that constructivist learning environment has positive effects on a learner-centred education process across disciplines. In an article by Mvududu (2005), the author asserts the positive effects of constructivist learning in the statistics classroom. Bostock (1998) concludes in his article that constructivist learning has applied well in mass higher education accommodating various learning styles of students, experience and attitudes. Even entrepreneurship education has been well supported by constructivist learning principles (Lobler, 2006). Several studies comparing teacher-centred and student-centred learning (Yuen \& Hau, 2006; Tynjala; 1998; Atlun \& Buyukduman; 2007) posit that student oriented learning or constructivist teaching has high impact over traditional teacher-centred teaching. Constructivist learning environment has created a yielding impact in Internet education as well (Tsai, 2007) where "students have more control over their learning time and pace." Atlun \& Buyukduman (2007) concludes in their article that constructivist instructional design has been found effective in the tertiary education.

Conventionally, a constructivist teaching strategy sets on the belief that students learn best when they acquire knowledge through social exploration and active learning. The instructor acts as a facilitator, coach, analyzer instead of textbooks, and students are encouraged to think and explain their reasoning instead of memorizing and reciting facts. Learners engage in defining the task, gathering ideas, observing and reflecting on their ideas when the society and the learners are interconnected. They can grasp and understand concepts when they are put in authentic rich learning environments. The process of socially interacting with an expert fosters and stimulates learning and gradually advances the learner into the culture of the profession (Gardner, 1991).

\section{TRADITIONAL COMMUNICATION TO A CONSTRUCTIVIST COMMUNICATION SKILL INSTRUCTION}

Communication is integral for the existence of any society. Communication is pervasive in all activities of the organization. In addition, rapidly changing technologies and a diversified workforce have resulted in new developments in today's corporate environment (Huang \& Kleiner, 2005). The knowledge in keeping au courant with these changes is highly vital for a learning individual. While organizations survive rigidly today with effective communication strategies, the type, frequency and nature of communication varies. Academics edify communication as a functional entity of the organization. But it is substantial to understand how communication is embedded and inter-connected to the various sub-units of the organization.

In their book on Communication in Organizations, Rogers and Agarwala-Rogers (1976, p.7) describes communication from an open system perspective as: 
.....is an important work tool through which individuals understand their organizational role, and integrates organizational sub-units. From an open systems perspective, an organization is an elaborate set of interconnected communication channels designed to import, sort and analyze information from the environment and export processed messages back to the environment. Communication provides a means for making and executing decisions, obtaining feedback and correcting organizational objectives and procedures as the situation demands.

The text book (Business Communication) used by the university students constitutes elements on fundamental concepts of business communication, interpersonal and intercultural communication and focuses on routine and non-routine messages flowing within organizations and across organizations that include positive, neutral, negative and persuasive messages. The classroom learning usually comprises of a combination of lectures, discussion and application of communication activities. While classes usually focussed only on the 'how-to' of the communication activity, learners were not aware how these theories and principles (in what form, nature and context) applied in the workplace. Therefore, it became pertinent that learning become observable and contextualised. This paper, therefore, describes such a constructivist pedagogy applied into the business communication curricula of a tertiary education sector, results of the method applied, from the employee and student perspective, and finally concludes with discussion.

\section{METHODOLOGY}

This constructivist learning task was initially introduced and elucidated to students, majored and nonmajored, enrolled in the Business Communication course which is a core subject of the college. The objective of this learning is

- $\quad$ To gain a thorough knowledge of organizational administration

- $\quad$ To gain an insight into the functional areas of management

- $\quad$ To understand the various departments of the organization

- To relate communication and its activities to the overall functioning of the organization

- $\quad$ To write and present the reflections relating to the task

The tools used for this learning task were mainly workplace observations and interviews with employees followed by reports, records, books, pamphlets, brochures, newsletters etc. Each student enrolled in the Business Communication course have to choose an organization (private or public) based on their majored subject and where they would like to be employed in the future. Duration of one week is given to them for selecting the organization. Within the given time, each student had provided the contact details of the organization to the instructor. The instructor also asked the student to choose another organization if there is any replication of organization selection within the class. Students enrolled in this course underwent the study for about six to seven days to meet the abovementioned first four objectives of the assignment. The key learning components to be dealt from the study were

- $\quad$ Analysis of the company

- $\quad$ Functional areas /Departments

- $\quad$ Communicative nature of the organization

Covering the first part of the study, students had to gain a thorough knowledge of organizational dimensions like the history and nature of company, type of ownership, market share, important milestones of the organization, main investors, shareholders, international associations and collaborations, the local competitors, important accreditations or certifications of the organization, the mission and vision statement of the organization, names of personnel at upper level management, organizational structure, types of products and services, developmental plans for the future etc. Students sought and relied information from interviews with employees, reading and analysing websites, newspapers, books, pamphlets, company brochures etc. 
The second part of the study had emphasized on gaining in-depth knowledge on departments within the organization which included the titles of various departments, main activities of few departments, department composition, integration of activities across departments, nature of information flow within and across department, sales and promotional strategies. Information was mainly attained for this section from observations and interactions with employees.

The third and most prominent part of the study was on analysing the communication practices in the organization. Students were asked to find out how the theoretical aspects of communication fit in actual practice. Students chose an official from the organization and through an in-depth interview find out the nature of communication activities performed under their work profile, flow of communication, observed the communication activities of the employee and found out how the theories and concepts of communication actually applied at the workplace. Students were asked to collect and attach the interviewee's business card. Almost all students had spent about six to seven days in the organization for collecting the required data.

Some of the questions for analysis of communication practices formulated by the students from their textbooks are as follows:

- What documents are normally written by you on a day-to-day basis?

- Do you deliver bad-news messages to your customers or colleagues? If yes, how do you put across the message?

- How do you see the importance of meetings to your organization?

- What channels of communication do you frequently utilise to communicate?

- How important are reports? What types of reports are normally written by you?

- How important are presentations? What is the nature of the presentations that you deliver?

- Do conflicts arise in the organization? If so, please cite an example and also shed some light on how you dealt with it.

- What important considerations should one have when dealing/ talking business with an Omani and nonomani?

- $\quad$ How do you analyze your customer while conducting business?

- Grapevine communication exists when employees don't receive information they want to know. Is this a healthy perspective?

- What are some of the cultural barriers you encounter in a multicultural setting?

- $\quad$ Do letters still hold an important place in your organization? How?

- What are some of the positive gestures used in your culture?

- What communication skills are important for your job profile?

- What are some of the common examples of routine messages that you receive on the job?

- How do you perceive technology as an essential communication apparatus?

\section{(From Student Portfolios)}

Information pertaining to this section was acquired through interviews with employees and observations.

Students, finally, were asked to write a report covering all the above components that was mentioned for this study and also give a brief presentation on their observations and reflections towards this learning task. This task was assessed in terms of the feedback from the employees, the content of their report and the presentation that was made. The results of this task were interpreted through qualitative paradigms which are described below along with the results. 


\section{RESULTS}

\section{Employee Perspective}

A form was designed by the instructor for the employee(s) whom the students had contacted and interviewed. The form mainly consisted of open-ended questions regarding the student's approach and allegiance towards learning of the organization. Employees were asked to evaluate the learner's seriousness towards the study. Through retrieval and analysis of these forms, the instructor found that most of the employees felt that the students were dedicated and serious towards this task. A few of them expressed that the questions posed by the students were somewhat fragmentary and ambiguous. However, some had suggested that students spend more time at the organization to gain an in-depth practical experience. Few employees, at the top-level and middle level management, however, unveiled willingness to train and hire some of the students after their graduation. Since most of the organizations in Oman (public and private) are at the helm of omanising (employment of Omani nationals) its human resources, organizations have always demonstrated a high interest in training, recruiting capable and hard working graduates.

\section{Student Perspective}

Students who were enrolled in this course were majored as well as non-majored students. The majored students were undertaking subjects in Accounting, Operations Management \& Business Statistics, Management, Marketing, Information Systems, Economics and Finance. Most of the students had chosen and received approval from the organization where they desire to work in the future while few of them had chosen organizations near the campus due to the ease of transport facilities. Student's feedback towards this learning task was solicited through semi-structured interviews. Questions were asked about the benefits that they acquired from this activity and also the problems that they encountered during their study. It was found from the interviews that almost all students attained a positive impact on their learning as a result of this pedagogical instruction. Some of the comments included:

- $\quad$ This was a good start to get acquainted with the business industry right after school.

- I know the activities that flow in the workplace and how they are connected with one another.

- $\quad$ It was easy to understand communication components that apply in workplace.

- I learnt how big organizations like banks work

- $\quad$ I learnt how to interview employees starting from setting up an interview to thanking them

- I have learnt from observations that employees should deal with customers carefully in order to make them feel that they are big assets of the company.

- $\quad$ Though I have majored in finance, I know the functions of the other departments in the organization.

- $\quad$ I could use my communication skills and also improve them while talking to the employees

- $\quad$ This is the first time I am seeing a working environment in the process, I took notes from their (employees) explanations and also learnt how to ask questions.

- I got a chance to meet new people in the industry....this will be helpful when I start to search for a job

- I liked the work carried out by HR professionals in the organization. I think I will join their group in the future, insha-allah.

- We should have activities like this in every course that we learn. The knowledge I gained will help me for other courses as well.

Although, students have highly expressed the advantages of this learning, the problems they encountered during the study cannot be disregarded. Some of the female students expressed logistical constraints to the companies. Few students felt that the time taken for this study was insufficient due to other courses and workload. 


\section{DISCUSSION AND CONCLUSION}

It can be well concluded that this instructional design based on the employee and student testimony emanating from both sides is beneficial and provides a rich authentic learning environment. The following points can be observed as a result of constructivist pedagogy:

- This learning has enabled students to transfer their textbook theories and applications from a teachercentric mode to the workplace environment, a student-centric mode, enabling an authentic learning scenario.

- $\quad$ Although these students, in their second or third year of college, are witnessing the workplace for the first time, this learning environment has set future links for most of them with the employees and employers from the organizations.

- $\quad$ The constructivist mode of learning has enhanced the students' internal learning capacity. Through interactions with students in classroom post-study, the instructor found that their knowledge was constructed effectively resulting in a comprehensive understanding of the work environment and related concepts through meaningful contexts.

- Social interaction is an important denominator of the constructivist learning. Students were closely interacting with the employees for effective knowledge construction through asking questions and also validating their understanding fostering effective learning.

- Interpersonal skills, research skills, interviewing skills, networking skills are developed as a result of this type of learning.

- Learners' gain a gamut of knowledge in other disciplinary areas of the organization as well. That is, a majored student in finance has sufficient knowledge in sales \&marketing division, Information systems, Operations department, Human resources department etc.

- $\quad$ This mechanism of learning promotes increased student engagement and elevated motivation in the overall learning process.

This learning task was instrumental in motivating the learners and building their cognitive skills. Observations and interactions, the main tools of the learning process, "takes on new meaning when viewed from the perspective of a constructivist rereading" (Arnaud, 2002). The overall knowledge of business and communication practices was well construed by the learners through the above mentioned learning process. This task allows students to bring in real-world experiences to the classroom and also apply it in other disciplines as well. Therefore, this paper suggests that students need to be engaged in the industry that involves authentic learning right from their commencement of university business education. It appears to be important that social interaction within the environment aids in grasping concepts and functions and observe the place that will take them to the future. This field experience allows investigation and experimentation in learner development; therefore learning institutions need to approach the curriculum in a learner-centred fashion with emphasis on learner investigation, reflection and discourse (Fosnot, p 206). Further studies like empirical research needs to be undertaken to validate constructivist approach in learning business and communication concepts.

\section{REFERENCES}

1. Altun, S. \& Buyukduman, F.I. (2007). Teacher and Student Beliefs on Constructivist Instructional Design: A Case Study. Educational Sciences: Theory \& Practice, Vol.7, No. 1, pp 30-39.

2. Arnaud, G. (2002). Developing in-company research: a French review of observation strategies. Management Decision, Vol. 40, No.2, pp.101-115.

3. Billet, S.R. (1993). Authenticity and culture of practice. Australian and New Zealand Journal of Vocational Education Research, Vol. 2 pp. 1-29.

4. Bostock, S.J. (1998). Constructivism in mass higher education: a case study. British Journal of Educational Technology, Vol.29, No.3, pp.225-240.

5. Brown, J.S., Collins, A. \& Duguid, P. (1989). Situated Cognition and the Culture of Learning. Educational Researcher, Vol. 18. No.1, pp.32-41. 
6. Fosnot, C.T. (1996). Constructivism: A psychological theory of learning. In C. T. Fosnot (Ed.) Constructivism: Theory, Perspectives and Practice. New York: Teachers College, Columbia University.

7. Gardner, H. (1991). The unschooled mind: How children think and how schools should teach. New York: Basic Books.

8. Gill A., \& Lashine S. (2003). Business Education: a strategic market-oriented focus. International Journal of Educational Management, Vol. 17, No.5, pp.188-194.

9. Gulbahar, Y. \& Tinmaz, H. (2006). Implementing Project-Based Learning and E-portfolio Assessment In an Undergraduate course. Journal of Research on Technology in Education, Vol.38, No.3, pp. 309-322.

10. Hodkinson, P. (2005). Reconceptualising the relations between college-based and workplace learning. Journal of Workplace Learning, Vol.17, No.8, pp. 521-532.

11. Huang, N. \& Kleiner, B.H. (2005). New Developments Concerning Corporate Communications. Management Research News, Vol. 28. No. 10., pp.57-64.

12. Jonassen, D.H. (1999). Designing constructivist learning environments. Instructional Theories and Models (pp.215-239). $2^{\text {nd }}$ ed. Mahwah, NJ:Lawrence Erlbaum Associates.

13. Kolmos, A. (1996). Reflections on Project Work and Problem-Based Learning. European Society for Engineering Education, Vol.21, No.2, pp. 141-148.

14. Kozulin, A. (1986). Vygotsky in Context, Preface to Vygotsky, Thought and Language. Cambridge, MA: MIT Press.

15. Lave, L., \& Wenger, E. (1991). Situated learning: Legitimate Peripheral Participation. Cambridge, England: Cambridge University Press.

16. Lobler, H. (2006). Learning entrepreneurship from a constructivist perspective. Technology Analysis \& Strategic Management, Vol.18.No.1, pp.19-38.

17. Mvududu, N. (2005). Constructivism in the Statistics Classroom: From Theory to Practice. Teaching Statistics, Vol.27,No.2, pp.49-54.

18. O'Connor, B.N. (2004). The Workplace Learning Cycle. A problem-based curriculum model for the preparation of workplace learning professionals. Journal of Workplace Learning, Vol. 16, No.6, pp. 341349 .

19. Piaget, J. (1963). The origins of intelligence in children. New York: W.W. Norton \& Company, Inc.

20. Rogers, E.M, Agarwala-Rogers, R (1976). Communication in Organizations, London: The Free Press.

21. Smith, P.J., Henry, J., \& Munro, G. (2002). Training young people through school/enterprise partnership: a longitudinal study. Education + Training, Vol 44, No. 6, pp. 281-289.

22. Tsai, C.-C. (2007). The preferences toward constructivist Internet-based learning environments among university students in Taiwan. Computers in Human Behavior, doi:10.1016/j.chb.2006.12.002

23. Tynjala, P. (1998). Traditional Studying for examination versus constructivist learning tasks: Do learning outcomes differ? Studies in Higher Education, Vol.23, No.2, pp.173-189.

24. Vygotsky, L.S. (1978). Mind in Society: The development of higher psychological processes. Cambridge, MA: Harvard University Press.

25. Yang, B., \&Lu, D. (2001). Predicting academic performance in management education: an empirical investigation of MBA success. Journal of Education for Business, Vol. 77 No.1, pp.15-20.

26. Yuen, K.M. \& Hau, K.T. (2006). Constructivist teaching and teacher-centred teaching: a comparison of students' learning in a university course. Innovations in Education and Teaching International, Vol.43 No. 3, pp. 279-290. 